\title{
Spend Less, Get More? Explaining Health Spending and Outcome Differences Between Canada and Italy
}

\author{
LIVIO DI MATTEO* \\ Lakehead University \\ THOMAS BARBIERO \\ Ryerson University
}

\begin{abstract}
Canada spends more than Italy on health per capita and as a share of GDP and has a higher per capita GDP. Yet, life expectancy and infant mortality in Italy are better and have improved more over time. The implication is that the Italian health care system provides better value for money. We examine whether Italy does get better health outcomes at lower costs. Using regression analysis, we find that health spending is determined by similar drivers in both Canada and Italy. We also find that more social spending and health spending in either country do not satisfactorily explain the differences in health outcomes, suggesting the importance of broader socio-economic determinants like income and lifestyle choices. We conclude that while the levels of per capita health spending in Canada are higher than Italy, this partly reflects historical inertia in Canadian health spending partially attributable to the higher costs of health professionals relative to Italy.
\end{abstract}

Keywords: health, expenditures,outcomes

JEL classifications:I1, I3, F0, H1, N3

\section{Introduction}

Canada and Italy are G7 countries with publicly funded universal health care systems that provide high quality health care. International rankings usually place Canada and Italy highly on health care performance. However, these rankings also often place Italy ahead in terms of health outcomes, even though when measured as a percentage of GDP and per capita expenditures Canada devotes more resources to health. For example, the WHO $2010^{1}$ rankings placed Italy second and Canada $30^{\text {th }}$ in terms of health system performance, while a more recent study in the Lancet $2018^{2}$ placed Italy ninth and Canada fourteenth. Meanwhile, in terms of

(C) 2020 Livio Di Matteo and Thomas Barbiero . Licensed under the Creative Commons Attribution Noncommercial 4.0 License (http: / / creativecommons.org/licenses/by-nc/4.0/) . Available at http: / / rofea .org.

${ }^{1}$ World Health Organization (2010).

${ }^{2}$ R. Lozano et al., (2018). 
spending as a share of GDP, a recent report placed Canada third and Italy twenty fourth. ${ }^{3}$

Recent research shows that more health spending does not always result in improved outcomes ${ }^{4}$ and that "Expensive health care is not always the best health care." ${ }^{5}$ The literature suggests that other social determinants also influence health outcomes. For example, Rowlingson (2011), Subramanian and Kawachi (2004) and Lynch et al., (2001), draw the link between income inequality and mortality rates as well as health and social problems. Dutton et al., (2018) for Canada emphasize social spending at the provincial government level as a determinant of improved performance when it comes to life expectancy.

We compare health spending, health system parameters and outcomes in Canada and Italy to answer why Italy spends less on health care and yet has generally obtained better long-term outcomes as measured by life expectancy and infant mortality. This disparity in long-term outcomes is apart from the early differential performance of the two countries with respect to the impact of the Covid-19 pandemic which cannot be properly addressed until a longer-term perspective becomes available. ${ }^{6}$

The difference in long-term outcomes and performance may be rooted in the structure of the health and social expenditure network and support system in the two countries. Notably, Italy devotes much more to redistributive schemes compared to Canada, and this difference might explain its better long-term health outcomes. We also consider differences in basic health care inputs and institutions that may account for the disparity in health outcomes in the two countries. The efficacy and efficiency of the healthcare system is a pressing question in all advanced countries as they face the public health shocks from events such as the Covid-19 pandemic and aging populations that will put pressure on future government budgets. We also find that while Canada does spend more but get less given its level of spending, the health dollars spent at the margin seem to have yielded the same benefits in terms of life expectancy increases and infant mortality declines in both countries.

The paper is divided as follows. First, we review the health care literature with respect to value for money in health care spending to provide context. Second, we overview the size,

\footnotetext{
${ }^{3}$ Barua, B., S. Hasan and I. Timmermans (2017) Comparing Performance of Universal Health Care Countries, 2017. Fraser Institute.

${ }^{4}$ Ariste and Di Matteo (2017).

${ }^{5}$ OECD (2009) Health At a Glance. https://www.oecd.org/ health/expensivehealthcareisnotalwaysthebesthealthcaresaysoecdshealthataglance.htm

${ }^{6}$ https://www.worldometers.info/coronavirus/\#countries. Italy was hit early by the coronavirus and has less warning and thus, the Covid-19 pandemic in Italy was initially more pronounced than Canada, with dire consequences for the mortality rate. However, the situation continues to evolve and as of the end of July, total Italian deaths per one million population since the start of the pandemic exceed Canada's total but on a current weekly basis, Italian deaths are now below Canadian.
} 
structure and financing of the two health care systems and compare aggregate health care spending in Canada and Italy, health care resource inputs, health care status indicators and outcomes, and social spending and income inequality. We then carry out a regression analysis to assess the determinants of health expenditures and use it to present a spending counterfactual simulation. We also estimate the determinants of health outcomes - namely, life expectancy at birth and infant mortality. The paper concludes with a discussion as to what factors help explain the differences in expenditures and health outcomes between Canada and Italy.

\section{Value for Money in Health Care: A Brief Review of the Literature}

\subsection{Health Spending and Health Outcomes}

In a world of unlimited wants and scarce resources, efficiency, or getting value for money, is paramount. Getting the most out of inputs, such as diagnostic machinery, the number of doctors, and hospital beds, can translate in extending the length and quality of life.

Input costs can be measured in monetary terms, such as the per capita spending on health care, or in physical terms, such as the number of hospital beds and technical equipment. ${ }^{7}$ Outcomes can be quantitative (lives saved or years of life gained), or qualitative (quality of additional years of life). A standard approach to efficiency in health economics is costeffectiveness analysis - that is a comparison of costs or expenditures per unit of health outcome. ${ }^{8}$ Health outcomes can be measured in terms of key indicators such as life expectancy at birth, mortality rates, or what are sometimes referred to as Quality Adjusted Life Years. ${ }^{9}$ Measures of health system cost-effectiveness and value for money could include health costs per quality adjusted life year, or measures of health spending per additional year of life expectancy or mortality rate reduction. ${ }^{10}$

\footnotetext{
${ }^{7}$ There are also recent studies of health care system input costs at the international level and particularly the EU. See Joumard, André and Nicq (2010), Asandului, Roman and Fatulescu (2014), and Medeiros and Schwierz (2015).

${ }^{8}$ See Folland, Goodman and Stano (2017: 81-107).

${ }^{9}$ A quality adjusted life year is a valuation of a year of life that assigns values between 0 and 1 to represent quality of life in each year. As another example, the Canadian Institute for Health Information (CIHI) (2014) suggests another approach to measure a health care system: the reduction in potential years of life lost (PYLL) from treatable causes of death. According to their results, the reduction in PYLL in Canada from treatable causes of death could be anywhere between 18 and 35 percent, depending on the province, which translates to preventing between 12,600 and 24,500 premature deaths CIHI (2014:2). In a separate study, the CIHI found that the PYLL for Italy for the year 2010 was lower than it was for Canada suggesting a more cost effective or efficient health care system given the greater per capita health spending in Canada CIHI (2016).

${ }^{10}$ For a discussion of measurement of cost-effective and value for money, see Artiste and Di Matteo (2017).
} 
The connection between expenditure on health and outcomes is not necessarily monotonic. Indeed, the research on the relationship between health spending and health outcomes often shows an ambiguous relationship. Some OECD countries, such as Spain, have high life expectancy, but with spending on health care in the middle of the pack. Belgium and Denmark rank high in spending but have only average health outcomes. Thus, we find in general a nonlinear relationship between health spending and outcomes, at least among European OECD member countries ${ }^{11}$.

Babazono and Hillman (1994) analyzed 1988 data for OECD countries, including Italy, and show that total health care spending and outpatient and inpatient utilization rates of the health care system are not related to health outcomes. On the other hand, Anderson et. al (2000) look at health spending and outcomes for OECD countries for the 1960-1998 period and find a positive relationship between health care expenditures and health outcomes, particularly so with regards to the U.S.A.

Golinelli et al., (2018) found mortality rates in Italy between 2011-14 increased because of government spending restraint, compared to the 1995 to 2010 period, implying that health expenditures do impact outcomes. However, citing Stuckler et. al (2010), they note that health spending cannot be considered the only determinant of mortality rates. In fact, Vercelli et. al. (2014) find mortality rates in Italy declining at a steady rate from the beginning of the $20^{\text {th }}$ century, right up to 2008, while national income growth was more variable.

Anderson and Frogner (2008) also find a tenuous relationship between health expenditures and health outcomes. They note that the U.S. had one of the highest per capita spending levels on health care in the world, yet it was equally likely to be at either the top or bottom of sixteen quality measures complied by the OECD.

Other studies have also found a relatively small impact of health care spending. Among these are Filmer and Pritchett (1999), and Nolte and McKee (2004). As well, Nixon and Ulman (2006) emphasize the complexity of associating health expenditures with outcomes, and found that for 15 European nations, including Italy, between 1980 and 1995, increases in health care spending improved infant mortality, but only a marginal impact on life expectancy.

Cremieux et. al. (1999) analyzed Canadian provincial data for the period 1978-1992 and found less spending on health care in Canada lead to an increase in infant mortality and life expectancy (LE). Namely, a 10\% reduction in health care spending increased infant mortality by $0.5 \%$ and decreased LE by 6 months for men and 3 months for women. Cremieux et. al. (2005a, b) focused on the impact of spending on pharmaceuticals in Canada on health outcomes and found a strong positive relationship on the LE and infant mortality. On the other hand,

${ }^{11}$ Madeiros and Schwierz (2015) 
Guindon and Contoyannis (2012) found no impact on health outcomes with increased spending on pharmaceuticals.

Joumard et.al. (2010) take a more comprehensive input-output approach in comparing OECD countries relative efficiency. They find both the Canadian and Italian system to be quite efficient, but the Italian health care systems has a lower mortality rate. On an efficiency basis, Medeiros and Schwierz (2015) find that the Italian health care system is one of the top performers in terms of the amount spent on health care and outcomes, placing second on its constructed efficiency scale, just behind France, which spends more on health care. Thus, Italy is not far from the "efficiency frontier," according to their analysis.

\subsection{Social Spending, Income Inequality and Health Outcomes}

Health outcomes stem from a production function process in which health care or health spending is only one input, along with with additional socio-economic determinants. ${ }^{12}$ The broader determinants of health approach can include the role of schooling, spending on social programs and income inequality. Social spending is a large category that in the broadest sense is ultimately about income redistribution. It may include welfare payments due to various physical or mental challenges, employment insurance programs, affordable housing programs, tax breaks for social purposes or low-income families, and direct in-kind provisions of goods and services targeting disadvantaged groups.

Some research shows social spending has important health effects on a population. On the topic of the role of social spending on infant mortality and birth outcomes, Kim and Saada (2013) find that income inequality and social policies, such as maternal leave policies may help to explain the cross-country variations in these important issues.

Dutton et al., (2018) examine the association between health care spending, social programs and health outcomes in Canada using the ratio of social to health spending dollars. Using provincial data from 1981 to 2011 they find a 1-cent increase in social spending per dollar spent on health was associated with a $0.1 \%(95 \%$ confidence interval $[\mathrm{CI}] 0.04 \%$ to $0.16 \%)$ decrease in potentially avoidable mortality and a $0.01 \%(95 \%$ CI $0.01 \%$ to $0.02 \%)$ increase in life expectancy. However, this study used only provincial social spending excluding municipal and federal social spending and noted that the ratio of social spending to health spending across Canadian provinces was low.

Bradley and Taylor (2013) found social spending in OECD countries improves health outcomes. They point out the stark example of the health care system in the U.S., one of the most expensive in the world, which ranks poorly on health outcomes. On a per capita basis, the

${ }^{12}$ See Folland, Goodman and Stano (2017: 109-132). 
U.S. spends double the OECD average on health, but the outcomes are among the worst in the OECD. Their research show that social service spending in the U.S. was predictive of three key health outcomes: life expectancy, infant mortality, and maternal mortality.

Rubin et. al. (2016) make a similar point and show that old-age spending makes a significant contribution to better health outcomes. They suggest that social spending and protection may be more important to better health outcomes in societies in which income inequality is high. For the U.S., they find that unemployment and income maintenance are strongly correlated with better health outcomes across U.S. states, but social expenditures take time to translate into better health outcome.

Bradley et. al. (2011) using a pooled cross section of OECD countries in 2009 find that health expenditures were significantly associated with better health outcomes in only two of five health indicators (life expectancy and maternal mortality) while social services expenditures adjusted for GDP were significantly associated with better health outcomes in three of five indicators. The ratio of social expenditures to health expenditures was significantly associated with better outcomes in infant mortality, life expectancy and increased potential life years lost, after adjusting for the level of health expenditures and GDP.

Lynch et. al (2004) in a review of 98 aggregate multilevel studies found income inequality is not associated with health outcome differences in affluent countries. Despite the tenuous relation between income inequality and health outcomes, they do claim that reducing income inequality of the most disadvantaged populations will improve their health and thus the health of general population. Latif (2015) examined the effect of income inequality on health outcomes in Canada and found no significant impact, but that absolute household income in Canada had a significant positive impact on health status.

Wilkinson and Pickett (2015) in a literature review of epidemiological causal literature find support for the proposition that that income inequality affects population health and wellbeing. Wilkinson and Pickett (2011) made similar claims in their previous work. Snowden (2011) in a direct response to the Wilson and Pickett position on income and inequality and population health dissents and argues that health outcomes are the product of diverse influences that over time can impact life expectancy and other health indicators.

This paper contributes to the current literature by having a closer look at two of the G7 countries that devote different amounts to health spending, and with different social expenditures and lifestyle factors to determine the contributions to health outcomes. We want to gain insights on whether Canada or Italy is getting greater relative value for money. 
DI MATTEO, BARBIERO Health Spending and Outcomes in Canada and Italy

\section{Health System Overview: A Comparison of Health Expenditure, Indicators and Outcomes, and System Trends}

\subsection{Canada's Health System}

In Canada, federal and provincial governments finance public health spending but under the Canadian constitution the provincial governments deliver publicly funded health care to citizens, making for a decentralized health system with some variation in both expenditure levels and service provision as well as some reliance on market mechanisms for services. ${ }^{13}$ Indeed, the OECD puts Canada into Group 2 countries along with Belgium, Australia and France - countries with public insurance for basic coverage and private insurance beyond the basic coverage. ${ }^{14}$

Canadian public health care is not one public health care system, but is 14 publicly funded systems, given that there are ten provinces and three territories along with a federal government with its own health obligations for indigenous peoples, the military and the RCMP. Provincial and territorial government health expenditures are for insured health services and extended health care and are financed by own source revenues as well as federal government transfers to the provinces.

Canada's public health care system evolved in stages, starting with individual provincial initiatives that were followed by federal financing. In 1957, the federal Hospital Insurance and Diagnostics Act established cost-sharing for provincial hospital insurance plans while the 1966 federal Medical Care Insurance Act provides cost sharing for physician services also. Thus, health system financing in Canada involves several layers: 1) public services for medically necessary hospital, diagnostic and physician services, 2) a mix of public-private insurance covered services including drugs and home care and 3) entirely private services such as dental services and physiotherapy. ${ }^{15}$

Canadian health care is approximately 30 percent privately and 70 percent publicly funded, but the proportion varies across provinces, as well as within expenditure categories. ${ }^{16}$ Private sector health care expenditures include those from health insurance firms, out-of-pocket expenditures of individuals, and patient service revenue paid by private insurers for items such as preferences for private hospital rooms or charges for services not deemed medically necessary. It also should be noted that in Canada public finance differs from public provision.

\footnotetext{
${ }^{13}$ Marchildon (2019).

${ }^{14}$ OECD 2010, "Health care systems: Getting more value for money", OECD Economics Department Policy Notes, No.2.

${ }^{15}$ Martin et al. (2018)

${ }^{16}$ See: Canadian Institute for Health Information. National Health Expenditure Trends 2018, 1975 to 2017.
} 
Canadian physician expenditures are nearly entirely publicly financed with physicians behaving mainly as private independent contractors rather than salaried employees. ${ }^{17}$ Physicians in Canada have substantial autonomy and flexibility in their daily practices and access to physician services can sometimes be problematic with reliance on hospital emergency wards or walk-in clinics. ${ }^{18}$

Federal transfers for provincial-territorial government health spending are made under the 1984 Canada Health Act, which specifies the criteria under which provinces and territories get federal health transfers. Provincial health systems must be publicly administered, comprehensive in their coverage of insured services, universal in their coverage, must have portable benefits, and must provide reasonable access to insured services. There is some variation across provincial systems in terms of what medical services and drugs are covered by provincial plans, but health outcomes are remarkably uniform across provinces. ${ }^{19}$

In 2018-2019, the total value of the Canada Health Transfer to the provincial and territorial governments according to the Federal Department of Finance is expected to be \$CAD 38.584 billion dollars and is expected to increase to $\$ C A D 40.373$ billion by $2019-2020 .{ }^{20}$ These federal transfers provide about 20 to 25 percent of provincial government health expenditures, though the growth rate of these transfers changed after 2017 as a new transfer formula took effect. The growth rate of the Canada Health Transfer is now based on the growth rate of real GDP, subject to a 3 percent floor as opposed to the previous Health Accord escalator, which saw annual 6 percent increases. ${ }^{21}$

\subsection{Italy's Health system}

The OECD groups the Italian health care system in Group 6, along with those of Hungary, Ireland, New Zealand, Norway, Poland and the U.K - health care services provided by a heavily regulated public centralized system, with budgetary spending limits. ${ }^{22}$ Italy's publicly funded health care system (Servizio Sanitario Nazionale-SSN) was established in 1978 and modelled on Britain's National Health Service. It is a single payer system providing universal coverage for all Italians, with responsibility for the organization and delivery of health services residing with the 19 regions and two autonomous provinces.

\footnotetext{
${ }^{17}$ For a discussion see Di Matteo (2014).

${ }^{18}$ See Di Matteo (2014) and Clarke (2016).

${ }^{19}$ See Marchildon (2019) for further discussion.

${ }^{20}$ See: Department of Finance Canada. https://www.fin.gc.ca/fedprov/mtp-eng.asp

${ }^{21}$ Norris (2018).

${ }^{22}$ OECD 2010, "Health care systems: Getting more value for money", OECD Economics Department Policy Notes, No. 2. Canada in in Group 2, which also includes Australia, Belgium and France.
} 
The central government in Rome controls the tax-financed health budget, which defines the benefits that must be guaranteed to Italians and foreign residents. The regions are responsible for the organization, planning and the actual delivery of health services, through the local health authorities, Azienda Sanitaria Locale (ASL). The regions and the two autonomous provinces have substantial autonomy in how they structure their health care systems within the parameters established by the central government, including health care spending and delivery. However, it is the central government that allocates the bulk of the funds for healthcare, making it more centralized than the Canadian system. Still, regions can raise additional resources, making for some significant regional differences in per-capita health care spending (Cicchetti and Gasbarrini, 2016).

The SSN focuses on primary health care. All citizens register with a general practitioner, who is given strong financial incentive to keep costs low by prescribing pharmaceuticals and refer patients to medical specialists only as appropriate. All citizens have access to primary care 24 hours a day, 7 days a week through not only their primary physician, but also out-of-hours service walk-in clinics (guarda medica). In recent years, general practitioners have been given financial incentives to form group medical practices, following a multi-professional and multidisciplinary approach.

Since 2016, in an effort to improve efficiency through economies of scale, several regions have merged local health authorities into larger entities. Despite the central government's commitment to a national standard of health care to all Italian citizens, there are concerns over regional differences in population health status and equal accessibility to quality health services. ${ }^{23}$ Generally, northern and central regions have higher capacity, more advanced diagnostic machinery, and better patient perceived quality of health care compared to southern Italy. Thus, it is not surprising that a significant number of patients from southern Italy travel to northern regions to obtain care. According to the Ministry of Health, at least 30,000 patients a year from the regions of Campania, Calabria, and Sicily travel north seeking better health care. $^{24}$

Health care in Italy is primarily publicly funded with 24 percent of expenditures privately funded ${ }^{25}$. While the publicly funded health care share is higher than Canada, it is lower than France and England, where fully 93 and 90 percent of all health spending is publicly funded. Private health insurance plays a minor role in Italy, accounting for only about one percent of total health spending in 2014.

\footnotetext{
${ }^{23}$ OECD, 2017

${ }^{24}$ Ibid. To the extent that three-quarter of expenditures are public, we can say that the Canadian and Italian health care systems are similar.

${ }^{25}$ OECD, 2015.
} 
Total health care spending declined after the 2008 global financial crisis, and remained essentially flat for the following 5 years, but started rising again in 2014. Containing the cost of health care spending has been a main concern for Italy given its relatively high public debt to GDP ratio. In 2016, the central government embarked on a deficit reduction plan for hospitals in an effort to balance their accounts. In fact, the number of acute care hospital beds has dropped significantly since 2000 in response to national targets to reduce all bed numbers. As is the case in many OECD countries, the Italian government is looking for efficiency gains from its national health care system.

\subsection{Health Expenditure Comparison}

Data for comparing spending indicators and outcomes across Canada and Italy come from OECD Health Statistics. ${ }^{26}$ Figure 1 and Table 1 compare several health expenditure variables, Table 2 presents a comparison of health system resources, while Table 3 and Figures 2 and 3 look at key health and social outcomes.

Figure 1: Per Capita Public Health Spending, US PPP\$, Canada and Italy

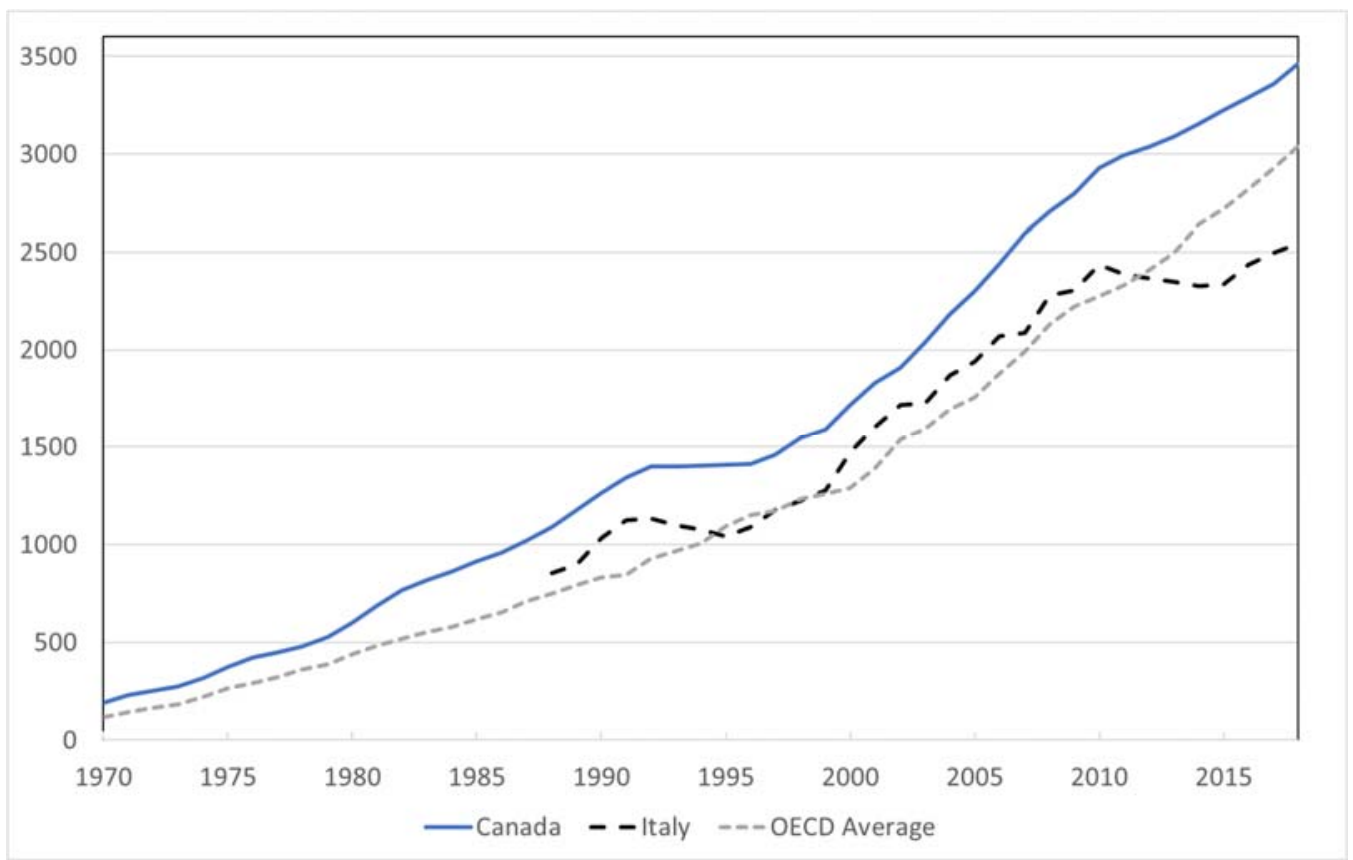

Source: OECD Health Statistics, 2019

${ }^{26}$ Assorted years, 2018 and 2019. http://www.oecd.org/els/health-systems/health-data.htm 
DI MATTEO, BARBIERO Health Spending and Outcomes in Canada and Italy

Table 1: Health Expenditure Summary Statistics: Canada, Italy, and OECD Averages

\begin{tabular}{|c|c|c|c|}
\hline & 1990 to 1999 & 2000 to 2009 & 2010 to 2018 \\
\hline \multicolumn{4}{|c|}{$\begin{array}{l}\text { Government and compulsory health insurance schemes, per } \\
\text { capita expenditure, US\$PPP }\end{array}$} \\
\hline Canada & 1422 & 2251 & 3172 \\
\hline Italy & 1128 & 1907 & 2408 \\
\hline OECD & 1048 & 1749 & 2630 \\
\hline \multicolumn{4}{|c|}{ Current expenditure on health, per capita, US\$PPP } \\
\hline Canada & 1985 & 3220 & 4505 \\
\hline Italy & 1505 & 2495 & 3186 \\
\hline OECD & 1463 & 2408 & 3508 \\
\hline \multicolumn{4}{|c|}{ Current expenditure on health, $\%$ of gross domestic product } \\
\hline Canada & 8.7 & 9.2 & 10.5 \\
\hline Italy & 7.1 & 8.2 & 8.9 \\
\hline OECD & 7.1 & 7.9 & 8.8 \\
\hline
\end{tabular}

There has been substantial growth in health spending over time in both Canada and Italy. However, as Figure 1 illustrates, Italian public sector health spending has more closely tracked the average for OECD countries, and stopped rising after the 2008-09 financial crisis. Canada spends more than Italy with respect to health whether we consider total spending, public spending, or health as a share of GDP. From the summaries in Table 1, over the period 2010 to 2018, Canada spent on average 32 percent more than Italy on per capita public sector health spending ${ }^{27}$ and 41 percent more with respect to total per capita health spending. As a share of GDP, total health spending in Canada in the 1990s, averaged 8.7 percent while it was 7.1 percent in Italy. In the 2010s it was 10.5 percent in Canada and 8.9 percent in Italy.

Table 2 presents average indicators by decade dealing with the deployment of resources in the Canadian and Italian health systems with OECD figures for comparison. Since the 1980s, physician density in Canada has fallen substantially below the OECD average, and since 2000 well below the Italian figures. While Canada began to increase physician supply after 2000, by the 2010s Canada was still below both the Italian and OECD averages at 2.5 physicians per 1,000 population, while Italy was at 3.9 , and the OECD average at 3.3.

${ }^{27}$ Defined as government and compulsory health insurance spending. 
Review of Economic Analysis 12 (2020) 403-438

Table 2: Health System Resources: Canada, Italy and OECD Averages

\begin{tabular}{|c|c|c|c|}
\hline & 1990 to 1999 & 2000 to 2009 & 2010 to 2018 \\
\hline \multicolumn{4}{|c|}{ Physicians, Density per 1000 population (head counts) } \\
\hline Canada & 2.1 & 2.1 & 2.5 \\
\hline Italy & & 3.7 & 3.9 \\
\hline OECD & 2.6 & 3 & 3.3 \\
\hline \multicolumn{4}{|c|}{ Nurses, Density per 1000 population (head counts) } \\
\hline Canada & 7.9 & 8.7 & 9.6 \\
\hline Italy & & 4.9 & 5.4 \\
\hline OECD & 6.6 & 7.6 & 8.6 \\
\hline \multicolumn{4}{|c|}{ Total hospital beds, Per 1000 population } \\
\hline Canada & 5 & 3.3 & 2.7 \\
\hline Italy & 6.3 & 4.1 & 3.3 \\
\hline OECD & 6.5 & 5.5 & 4.8 \\
\hline \multicolumn{4}{|c|}{ MRI units, total, Per million population } \\
\hline Canada & 1.1 & 5.4 & 9.2 \\
\hline Italy & 5.4 & 14.6 & 26 \\
\hline OECD & 3.5 & 8.1 & 14.5 \\
\hline \multicolumn{4}{|c|}{ CT scanners, total, Per million population } \\
\hline Canada & 7.6 & 11.6 & 14.9 \\
\hline Italy & 17.3 & 26.9 & 33.3 \\
\hline OECD & 14.3 & 17 & 24.1 \\
\hline \multicolumn{4}{|c|}{ Doctors consultations, Number per capita } \\
\hline Canada & 6.6 & 7 & 6.9 \\
\hline Italy & 6.5 & 6.1 & 6.8 \\
\hline OECD & 6 & 6 & 7 \\
\hline
\end{tabular}

While the Italian health system is more physician intensive than the Canadian one, the reverse is the case for nursing resources. While nurses per 1000 population has grown over time in both Canada and Italy, by the 2010s, there were on average nearly twice as many nurses per 1000 population in Canada compared to Italy. Nurses in Canada may be a partial substitute for both physicians and hospital beds, given that the number of total hospital beds per 1000 in Canada is below the Italian level. 
DI MATTEO, BARBIERO Health Spending and Outcomes in Canada and Italy

Medical diagnostic technology (MRI and CT scanners) has grown since the 1990s in Canada and Italy, but Italy has more units per capita of both technologies relative to not only Canada, but also the OECD. Again, Canada may be substituting intensity of labour utilization for capital when it comes to diagnostics relative to Italy because the evidence available in Table 2 shows slightly more physician consultations per capita on average in Canada over time, despite lower stocks of diagnostic equipment and fewer physicians per capita.

\subsection{Health and Social Outcome Indicators Comparison}

Table 3 summarizes some key basic health indicators of both health outcomes as well as potential correlates of some of those outcomes: infant mortality rates, life expectancy at birth (both sexes), suicide rates, tobacco and alcohol consumption and self-reported obesity rates. Figures 2 and 3 provide evidence on long term social outcomes as captured by social spending and inequality.

Both Canada and Italy have seen improvements in these basic health outcomes over time. Between 1960 and 2017, average infant mortality rates by decade in Canada declined by 81 percent from the 1960s to the 2010s. Italy's reduction was steeper, falling 92 percent. While annual data show that infant mortality in Italy fell below the OECD average in 1979 and has remained below it, infant mortality in Canada went above the OECD average for the first time in 2007, and has since remained above. Between the 1960s and the 2010s, average annual life expectancy at birth in Canada rose from 71.7 to 81.7 years, while in Italy it rose from 69.8 to 82.7 years. Of additional interest, suicide rates (intentional self-harm) in both Canada and Italy are below the OECD average, and both have declined since the mid-1980s with suicide rates in Italy dramatically lower than in Canada.

Tobacco consumption in Italy and Canada, like much of the OECD, has fallen steeply since the 1960s, but Italian consumption remains above both Canada and the OECD average. Alcohol consumption in Italy is now below the OECD average and below Canadian rates, with Italian decline starting in the mid-1970s. Both of these variables can be considered important lifestyle inputs into health outcomes. Finally, it should be noted that while self- reported obesity rates have been on the rise in both Canada and the OECD, they are lower in Italy.

Another comparison area is social spending and income distribution given their potential effect on health outcomes as noted in the broader social determinants of health literature. ${ }^{28}$ Italy has gradually surpassed Canada when it comes to basic health indicators such as longevity and infant mortality and one possibility is that Italy has achieved this because of greater social spending, or perhaps a more equitable distribution of income.

${ }^{28}$ Social spending and inequality may affect health stresses associated with differential positions in social hierarchies and status. See: Hurley (2010: 176-178). See also see Braveman, Egerter and Williams (2010). 
Review of Economic Analysis 12 (2020) 403-438

Table 3: Health Outcome Indicators: Canada, Italy \& OECD Averages

\begin{tabular}{|c|c|c|c|c|c|c|}
\hline & 1960-1969 & 1970-1979 & 1980-1989 & 1990-1999 & 2000-2009 & 2010-2017 \\
\hline \multicolumn{7}{|c|}{ Infant mortality, Deaths per 1000 live births } \\
\hline Canada & 24.2 & 14.7 & 8.3 & 6 & 5.2 & 4.7 \\
\hline Italy & 37 & 22.6 & 11.4 & 6.5 & 3.6 & 2.9 \\
\hline OECD & 30.2 & 20.1 & 12.4 & 8.4 & 5.6 & 3.9 \\
\hline \multicolumn{7}{|c|}{ Life expectancy, Total population at birth, Years } \\
\hline Canada & 71.7 & 74 & 76.2 & 78 & 79.9 & 81.7 \\
\hline Italy & 69.8 & 73.1 & 75.4 & 78.2 & 80.9 & 82.7 \\
\hline OECD & 69.5 & 71.2 & 73.6 & 75.6 & 78 & 80.2 \\
\hline \multicolumn{7}{|c|}{ Intentional self-harm, Deaths per 100000 population } \\
\hline Canada & 11 & 14.6 & 14.6 & 13 & 11.2 & 11.2 \\
\hline Italy & 6.5 & 6.7 & 8.1 & 7.6 & 6.1 & 6.1 \\
\hline OECD & 14.4 & 15.2 & 17.6 & 17 & 14.7 & 12.6 \\
\hline \multicolumn{7}{|c|}{ Tobacco consumption, $\%$ of population $15+$ who are daily smokers } \\
\hline Canada & 41.9 & 38.1 & 30.8 & 25.6 & 18.4 & 14.3 \\
\hline Italy & & & 32.1 & 25.7 & 23.3 & 21 \\
\hline OECD & 45.5 & 43.8 & 34.4 & 28.4 & 23.4 & 17.3 \\
\hline \multicolumn{7}{|c|}{ Alcohol consumption, Liters per capita (age $15+$ ) } \\
\hline Canada & 7.8 & 10.4 & 9.9 & 7.6 & 8 & 8.2 \\
\hline Italy & 18.9 & 18.43 & 13.5 & 9.9 & 8.2 & 7.3 \\
\hline OECD & 8.5 & 11.3 & 10.8 & 9.5 & 9.7 & 8.7 \\
\hline \multicolumn{7}{|c|}{ Obese population, self-reported, $\%$ of total population } \\
\hline Canada & & & & 13.5 & 15.8 & 18.7 \\
\hline Italy & & & & 7.9 & 9.4 & 10.3 \\
\hline OECD & & & 6.4 & 9.6 & 13.7 & 15.9 \\
\hline
\end{tabular}

Source: OECD Health Statistics $(2017,2018,2019)$

Both Canada and Italy have seen improvements in these basic health outcomes over time. Between 1960 and 2017, average infant mortality rates by decade in Canada declined by 81 percent from the 1960s to the 2010s. Italy's reduction was steeper, falling 92 percent. While annual data show that infant mortality in Italy fell below the OECD average in 1979 and has remained below it, infant mortality in Canada went above the OECD average for the first time 
DI MATTEO, BARBIERO Health Spending and Outcomes in Canada and Italy

in 2007 and has since remained above. Between the 1960s and the 2010s, average annual life expectancy at birth in Canada rose from 71.7 to 81.7 years, while in Italy it rose from 69.8 to 82.7 years. Of additional interest, suicide rates (intentional self-harm) in both Canada and Italy are below the OECD average, and both have declined since the mid-1980s with suicide rates in Italy dramatically lower than in Canada.

We use aggregated social expenditure data from the OECD. ${ }^{29}$ As a share of GDP, social expenditure has risen over time in both Italy and Canada, but Italy generally spends more (See Figure 2). For example, in 1980 Canada spent 13.3 percent of GDP on social programs, compared to 17.4 percent for Italy. Over the last approximately 40 years, that percentage has grown to 28.1 percent in Italy in 2017 and ultimately reached 17.3 percent in Canada after declining from a peak of 18.4 percent in 1995 in the wake of the intergovernmental transfer cuts of the federal fiscal crisis.

Figure 2: Social Expenditure as a Percent Share of GDP

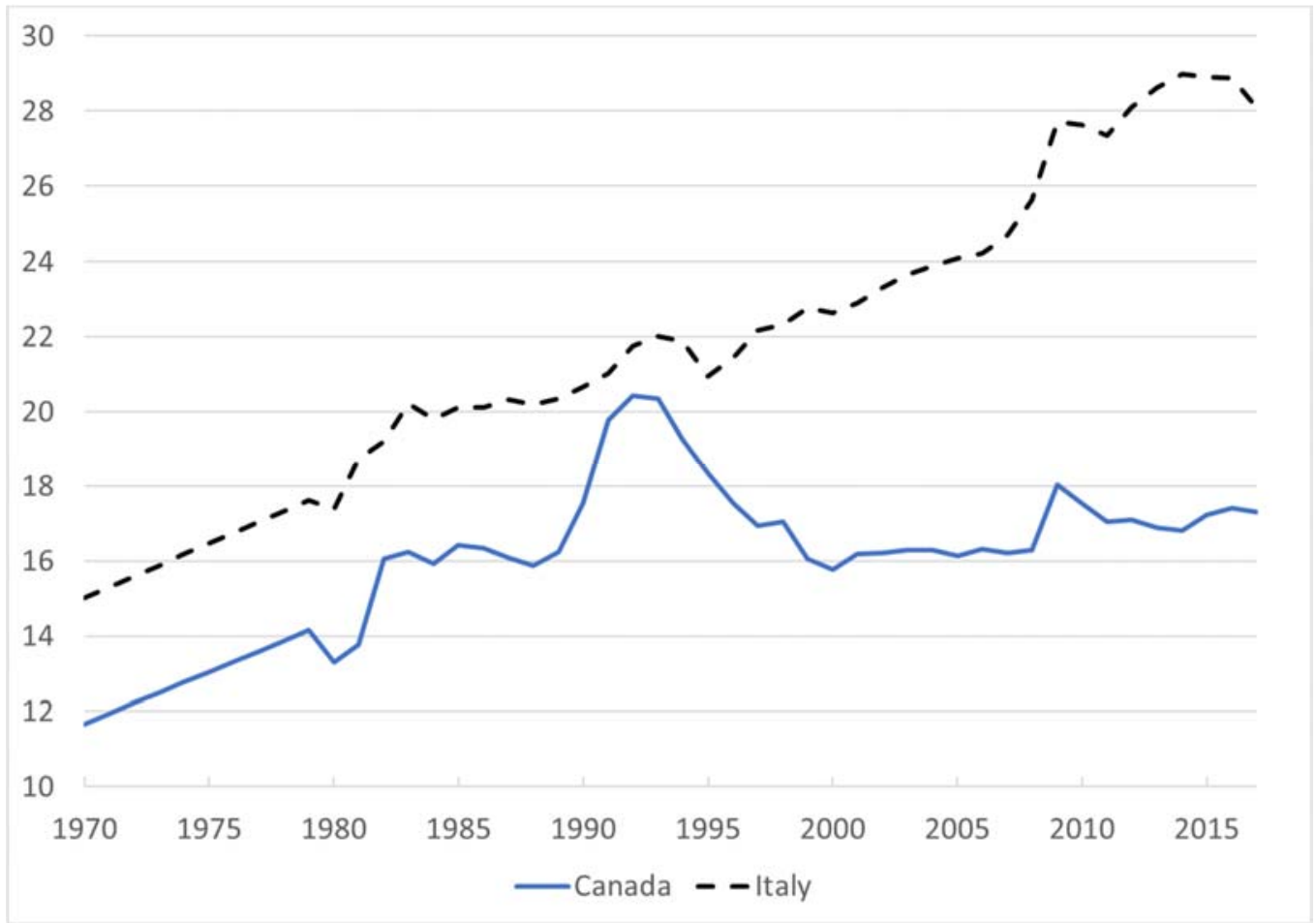

Source: OECD Stat. https://stats.oecd.org/Index.aspx?datasetcode=SOCX_AGG

${ }^{29}$ OECD Stat. https://stats.oecd.org/Index.aspx?datasetcode=SOCX AGG 
There are differences in social expenditure focus in the two systems. Public expenditures on old age and survivors cash benefits are higher in Italy, reflecting a more generous Italian social security system. In 1980 Canada spent 3.1 percent of its GDP on old-age related transfers, and this grew to 4.7 percent in 2015. In Italy it already reached 8.6 percent in 1980, and by 2015 it almost doubled to 16.2 percent. By comparison, the OECD average spending on old-age related transfers was 5.5 percent of GDP in 1980 and 7.5 percent in 2015.

Public expenditures on disability and sickness cash benefits are nearly double in Italy compared to Canada, at 0.8 percent of GDP in Canada and 1.7 percent in Italy in 2015. Direct public expenditures on family (in cash and in kind) were 1.5 percent of GDP in Canada, and 2 percent of GDP in Italy in 2015. Telling of the extent of the redistribution of income through social programs is the income of older people aged 65 and over, as a percent of the general population income. In 2014 those 65 years and older in Canada had 91.1 percent of the income of the general population, as compared with 98.8 for Italy, while the OECD average was 87.6 percent.

Figure 3: Top 1\% Percent Share of Adult Pre-Tax Income

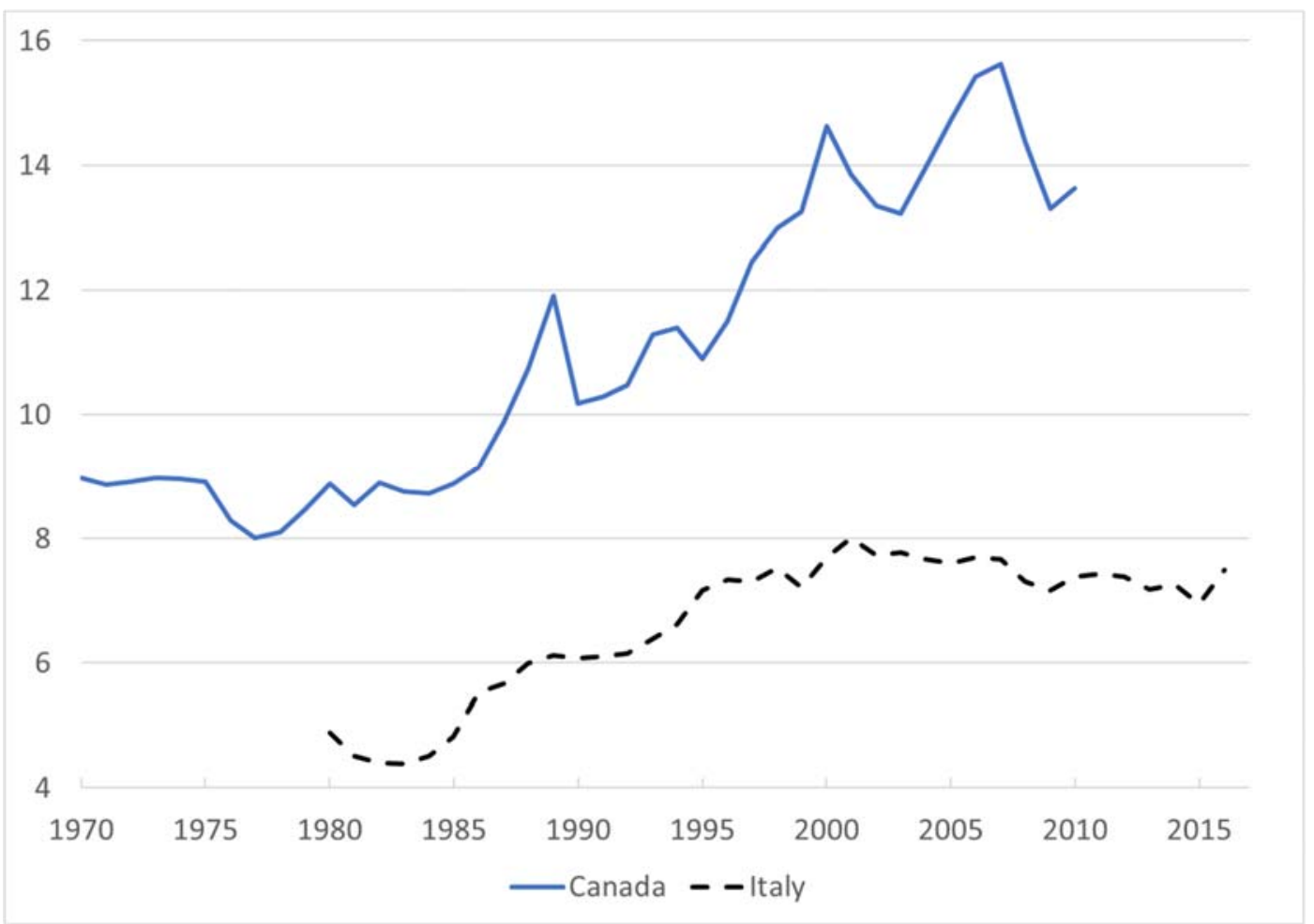

Source: World Inequality database https://wid.world/ 
DI MATTEO, BARBIERO Health Spending and Outcomes in Canada and Italy

With respect to income inequality, OECD Gini coefficients ${ }^{30}$ for Canada and Italy show that in 2016 Italy was slightly more unequal than Canada with a Gini of 0.33 , compared to 0.31 for Canada. However, measuring inequality as the pre-tax income share of the top $1 \%$ of adult earners, Canada appears to have greater income inequality than Italy. The income inequality data for Italy should be treated cautiously, since it has a relatively large shadow economy, ${ }^{31}$ making officially reported market income to construct inequality measures potentially unreliable.

Figure 3 plots the pre-tax income share of the top $1 \%$ of adult earners for Canada and Italy using data from the World Inequality Database. ${ }^{32}$ The top 1 percent of earners was used as the inequality measure given that more preferable Gini coefficient data was not available. While income inequality as measured by the top 1 percent of earners has grown in both countries over time, Canada has greater income inequality than Italy, at least before taxes and transfers are factored in. As noted, the relatively large size of the black-market economy in Italy compared to Canada means that these data may understate the extent of regional or individual level inequality.

To summarize, Canada spends more than Italy on health care, but Italy has surpassed Canada in basic health indicators like longevity and infant mortality. Despite spending more on health both per capita and relative to GDP, Canada per capita has fewer physicians, fewer hospital beds and less medical technology, but does have more nurses and physician consultations. Despite spending more, based on the basic health indicators of longevity and infant mortality Canada appears to be getting less.

\section{Methodology}

We conduct regression analysis on health care spending drivers and key health indicators to determine the responsiveness of health spending and health indicators to common determinants for Canada and Italy. Along with using the results to examine the determinants of health spending, the regression results are also used to conduct a counterfactual simulation.

\subsection{Regression Analysis}

There is an extensive literature on the determinants of health spending - both public and private - with key expenditure drivers including population growth, physician numbers given the gate keeping role of physicians, ${ }^{33}$ population aging, income, inflation, and enrichment factors such

$30 \mathrm{https}: / /$ data.oecd.org/inequality/income-inequality.htm

31 See Medina and Schneider, 2018 for a discussion.

$32 \mathrm{https} / / /$ wid.world/

${ }^{33}$ For a discussion see Di Matteo (2014). 
as technological change as often by diagnostic equipment usage or by time trend. These studies have been carried out at the national, international and regional levels. ${ }^{34}$

Even though Canada and Italy are very regionalized countries, we focus on national level determinants of health expenditures for several compelling reasons. First, while Canadian health care is delivered by the provinces with regional differences in per capita spending and services, health outcomes are consistently high across the country. Italy also has consistency in health outcomes across its regions, though there are regional differences in spending (Francese and Romanelli 2011) ${ }^{35}$. Second, the lack of available regional level data across a long enough time span for both spending, service provision and health outcomes make it impossible for our study to focus on regions. While sufficient and comparable time series going back to 1970 are either available or can be constructed at the national level, the data issue becomes more problematic at the region/province level. For Canada, provincial level health expenditure data is available going back to the mid-1970s from the National Health Expenditure Database of the Canadian Institute for Health Information. For Italy, the data sets for regional spending only go back to the 1990s.

Third, a high-level national comparison is better given institutional differences in the roles of regions/provinces in health care across Canada and Italy. Canadian provinces have considerably more autonomy in the areas of health and education spending than do Italian regions. Canada is a decentralized federation where the provinces deliver and fund health care, whereas in Italy, regional health care provision is accompanied by much more centralization with respect to funding and provision. Thus, our decision to rely on national level data.

We model the determinants of health expenditure in Canada and Italy as:

$$
\mathrm{H}_{\mathrm{t}}=\mathrm{f}(\mathrm{z} 1 \mathrm{t}, \mathrm{Z} 2 \mathrm{t}, \ldots . \mathrm{Znt})
$$

where $H_{t}$ is real per capita government health expenditures and $z_{1}$ to $z_{n}$ represent a vector of social, demographic, economic and policy variables at time $t$ which are determinants of $H_{t}{ }^{36}$

\footnotetext{
${ }^{34}$ See Constant et al., (2011). For an excellent survey of the international health expenditure determinants literature, see Gerdtham and Jonsson (2000). The first generation of such determinants studies often used international data. See Leu (1986), Parkin et. al., (1987), and Gerdtham et al (1992). See also Hitiris and Posnett (1992), Barros (1998), Gerdtham et. al, (1998), Di Matteo and Di Matteo (1998), Ariste and Carr (2003) and Crivelli, Filippini and Mosca (2006). For some more recent papers, see Cantarero Prieto and Lago Penas (2010), Magazinno and Mele (2012), Di Matteo (2010, 2014), Di Matteo and Emery (2014), Braendle and Columbier (2016), Nghiem and Connelly (2017), Yetim et al, (2020).

${ }^{35}$ Generally, the southern part of Italy has lower per capita healthcare spending. The regional differences in healthcare spending is partly offset by southern Italians travelling north for health care services.

${ }^{36}$ The variables are: PPP GDP Per Capita Current Prices; Population (millions); Unemployment Rate (\%); Total Health Exp to GDP (\%) HGDP; Per Capita Total Health Expenditure USPPP\$; Public
} 


\section{MATTEO, BARBIERO Health Spending and Outcomes in Canada and Italy}

The national level data for these regressions covers the period 1970 to 2017, and comes from OECD Health Statistics $2018^{37}$, supplemented by data from the World Bank, the OECD Social Health Expenditure Database ${ }^{38}$, the IMF WEO Database ${ }^{39}$, the World Inequality Database, ${ }^{40}$ and FRED. ${ }^{41}$ The specification is log-linear, and the estimation technique is Robust Regression which helps address the potential impact of outliers in data. ${ }^{42}$ We conducted Augmented Dickey-Fuller tests on the regression variables and found a high degree of stationarity across the variables in the dataset. ${ }^{43}$

Table 4 reports our results for per capita public and per capita total health expenditures. The final reported specifications regress the health expenditure variables on GDP per capita in U.S. PPP dollars lagged one year ${ }^{44}$ (a measure of long term income impact), the first difference of GDP per capita in U.S. PPP dollars (a measure of short term income fluctuations), physicians per 1,000 population, nurses per 1,000 population, the number of MRI machines per one million population (a variable to represent the impact of diagnostic technology on health spending), and the percent of population aged 65 years and over using a quadratic specification to reflect the fact that while aging populations can drive up health spending, eventually steps will be taken to restrain it making for a hump shape.

We find differences driving per capita health spending across the two countries. Lagged per capita GDP is a significant long-term driver of per capita Canadian health spending, but shortterm fluctuations in GDP are not, with opposite response to these two variables for Italy. It is unclear why per capita health spending is less responsive to the level of GDP in Italy compared to Canada, but given the significance of the first difference of GDP per capita for Italy (but not

Health Exp Per Capita USPPP\$; Infant Mortality Deaths per 1000 live births; Life Expectancy at Birth Years; Self Harm (Suicides) Deaths per 1000; Alcohol Consumption Litres Per Capita; Tobacco Consumption. \% pop 15+ who smoke; Physicians per 1000 Population; Medical Graduates Per 1000 Population; Nurses per 1000 population; Total Hospital Beds per 1000 population; MRIs per one million people; CTs per one million people; Doctor consultations Per Capita; Percent of population Aged 65 Years and Over; Social Expenditure Share of GDP (\%); Social Expenditure Per Capita USPPP\$; Top 1 Percent Pre-Tax Income Share.

${ }^{37} \mathrm{http} / / / \mathrm{www}$.oecd.org/els/health-systems/health-data.htm

${ }^{38} \mathrm{http}: / /$ www.oecd.org/social/expenditure.htm

${ }^{39} \mathrm{https}$ ://www.imf.org/external/pubs/ft/weo/2018/02/weodata/index.aspx

${ }^{40} \mathrm{https}: / /$ wid.world/

${ }^{41}$ FRED is the Federal Reserve Bank of St. Louis Database. See: https://fred.stlouisfed.org/

${ }^{42}$ It should be noted that while the data for these regressions is from 1970 to 2017, some of the variables did not have complete coverage and as a result gaps were filled using a regression that regressed the available data on time trend and the coefficients used to fit the data to the missing years.

${ }^{43}$ The ADF test was done employing no constant or trend and two lags. For most of the variables, the hypothesis of a unit root was rejected at the $5 \%$ and $10 \%$ level and occasionally at the $1 \%$ level.

${ }^{44}$ Initial specifications also included 2- and 3-year lags, but they were found to be of low impact. 
Table 4: Health Expenditure Determinant Regression Results

\begin{tabular}{|c|c|c|c|c|}
\hline \multicolumn{5}{|c|}{ Dependent Variable: Log of Per Capita Total Health Expenditure USPPP\$ } \\
\hline & \multicolumn{2}{|c|}{ Canada } & \multicolumn{2}{|c|}{ Italy } \\
\hline & Coefficient & t-statistic & Coefficient & t-statistic \\
\hline בGDP Per Capita in PPP Dollars Lagged One Year & 0.000039 & 4.06 & 0.000004 & 0.33 \\
\hline First Difference of GDP Per Capita in PPP Dollars & 0.000004 & 0.24 & 0.000039 & 1.91 \\
\hline Physicians per 1000 Populatoin & 0.498666 & 3.83 & 0.648925 & 2.32 \\
\hline Nurses per 1000 Population & 0.002573 & 0.10 & 1.187990 & 9.88 \\
\hline MRI per Million Population & -0.033041 & -1.9 & 0.010492 & 1.25 \\
\hline Percent of Population Aged 65 Years and Over & 0.749569 & 7.23 & -0.014850 & -3.81 \\
\hline Percent of Population Aged 65 Years and Over Squared & -0.026910 & -8.42 & -0.014850 & -1.89 \\
\hline Constant & 0.607742 & 1.00 & 0.903599 & 0.81 \\
\hline R-squared & 0.9028 & & 0.7639 & \\
\hline F-Statistic $(7,39)$ & 1349.63 & & 854.35 & \\
\hline \multicolumn{5}{|c|}{ Dependent Variable: Log of Public Health Expenditure Per Capita USPPP\$ } \\
\hline GDP Per Capita in PPP Dollars Lagged One Year & 0.000043 & 3.72 & 0.000014 & 0.77 \\
\hline First Difference of GDP Per Capita in PPP Dollars & 0.000001 & 0.08 & 0.000077 & 2.43 \\
\hline Physicians per 1000 Populatoin & 0.692374 & 4.44 & 0.545579 & 1.27 \\
\hline Nurses per 1000 Population & 0.000212 & 0.01 & 1.110165 & 6.00 \\
\hline MRI per Million Population & -0.042219 & -2.03 & 0.021116 & 1.64 \\
\hline Percent of Population Aged 65 Years and Over & 0.626672 & 5.05 & 0.249538 & 1.31 \\
\hline Percent of Population Aged 65 Years and Over Squared & -0.023560 & -6.16 & -0.016379 & -2.73 \\
\hline Constant & 0.808397 & 1.12 & 1.137162 & 0.67 \\
\hline Adjusted R-squared & 0.8962 & & 0.8270 & \\
\hline F-Statistic $(7,39)$ & 869.39 & & 321.66 & \\
\hline
\end{tabular}

Bold denotes significant at 5 percent level; Bold italics is significance at 10 percent level

for Canada) it may be that there is more sensitivity in Italian health expenditures to changing economic circumstances. Italian health spending is more centralized than Canada which means that changes resulting from resource fluctuations can be transmitted more rapidly across the system. ${ }^{45}$

\footnotetext{
${ }^{45}$ GDP per capita has gone up a bit more in Canada compared to Italy since 1990. In 1990 GDP per capita in Italy was US\$18.55K and in Canada US\$20.25k. In 2016 it was $44.92 \mathrm{k}$ in Canada and 39.04 in Italy: https://data.oecd.org/gdp/gross-domestic-product-gdp.htm. It should be noted that the data is $\underline{\text { PPP at current prices. }}$
} 
With respect to the impact of GDP on health spending, it is important to note Italy's shadow economy is generally held to be larger than Canada's. According to a study by the University of Tubingen in West Germany (IAW), as a percentage of GDP Italy's shadow economy was almost 20 percent (19.8\%), while Canada's shadow economy in 2017 is estimated at 9.8 percent. ${ }^{46}$ The relatively large shadow economy in Italy probably understate levels of GDP and GDP per capita. It should also be emphasized, that if GDP and GDP per capita are understated it could make the Italian health care system look more efficient, since it implies that Italy spends a lower percentage of its GDP on health care.

Physician numbers are positive drivers of spending in both Canada and Italy and the coefficient estimates suggest the response is weaker for Canada when it comes to total health spending, but greater for public health spending. We note that the larger coefficient on physician numbers in Canada as a determinant of public health spending relative to Italy may be due to family physicians being paid on a capitation basis in Italy, whereas in Canada the feefor-service approach still dominates. It is also possibly a function of physicians paid relatively more in Canada than Italy. In 2015 Canadian specialist physicians average gross income was 4.5 times more than the average wage while in Italy the ratio was $2.5 \cdot{ }^{47}$ As another example, in 2011, specialist physicians in Canada in US\$ PPP received annual remuneration of $\$ 213,000$ while in Italy it was $\$ 93,000 .^{48}$ The lower remuneration for Italian physicians partly enables a relatively larger number of medical doctors per 1000 inhabitants: In 2018 Italy had 3.9 doctors while Canada had 2.5. ${ }^{49}$ The number of doctors grew very rapidly in the 1970s and 1980s (Walton and Binns, 1984) in Italy, which put downward pressure on doctors' salaries. The rapid rise in the number of doctors in Italy in the 1970s and 1980s is attributable to the elimination of entry barriers in medical schools in the late $1960 \mathrm{~s} .{ }^{50}$ Students wishing to study medicine could enroll in the faculty of medicine of any Italian university.

However, the same explanation does not appear to hold for nurses. Nurses per 1,000 population is not a significant driver of Canadian health spending at either the total or public

\footnotetext{
${ }^{46}$ Reported in Forbes, February 9, 2017, https://www.forbes.com/sites/niallmccarthy/2017/02/09/wherethe-worlds-shadow-economies-are-firmly-established-infographic/\#7459be0c742c

${ }^{47}$ Source: OECD (2017), "Remuneration of doctors (general practitioners and specialists)", in Health at a Glance 2017: OECD Indicators, OECD Publishing, Paris.

${ }^{48}$ Remuneration of Doctors and Nurses: Progress and Persisting Issues. Joint Sessions of Health Data correspondents and Health Accounts Experts. Paris, 17 October 2013. OECD. https://www.oecd.org/els/health-systems/Item6_Remuneration-of-doctors-and-nurses_Durand.pdf.

${ }^{49}$ Italy has one of the highest numbers of medical doctors in the OECD. There are historical reasons for this. In the late 1960 s access to medical schools was made available to anyone that wanted to register for them and led to an explosion of graduates. See Walton and Binns (1984). For many years in the 1980 s and 1990s there were many unemployed medical doctors in Italy, which ultimately had an impact on doctors' salaries.

50 Thorne (1996).
} 
level but is for Italy. This is an intriguing result given Italy has more physicians but fewer nurses per capita than Canada, and Canadian nurses are paid substantially more than Italian nurses. Again, according to the OECD the remuneration of hospital nurses in US\$PPP in 2011 was $\$ 51,000$ in Canada and $\$ 37,000$ in Italy. ${ }^{51}$ This suggests that it is not numbers or costs alone, but perhaps differences in use and role of nurses in the health care process.

New diagnostic technology has a differential impact on spending across the two countries. For Canada, increasing the number of MRI units is associated with a decrease in per capita health spending at both the total and public level. For Italy, the result has been positive, though only significant for public health care spending and at the $10 \%$ level. Again, this suggests a potentially differential effect across Italy and Canada over time on per capita health spending from the introduction of new diagnostic technologies. Technological change can have costenriching effects if increased demand results from new procedures. Even if the new techniques generate less expensive health procedures, the ultimate impact on spending will depend on the interplay of the two forces. ${ }^{52}$

Finally, an aging population is a positive driver of health spending in both countries, but based on the coefficient sizes, the magnitude of the effect is greater in Canada. In both countries, the relationship between proportion of population aged 65 and over is a quadratic (hump-shaped). With respect to total per capita health spending, an aging population has its peak positive effect on health spending in Canada until the percent aged 65-and-over reaches 14 percent of the population, and for Italy when that percentage reaches 8 percent. This suggests that Italy may have moved earlier to deal with the costs of an aging population. However, it could also be a "statistical illusion" in that the over-65 population in Italy began to grow at an earlier period compared to Canada.

The efficacy of both health and social spending on life expectancy (LE) and infant mortality is considered in the regressions in Table 5. The log of life expectancy at birth and the log of infant mortality rates are regressed on the following key variables: lagged level of per capita GDP in U.S. PPP dollars, alcohol consumption per capita (litres), tobacco consumption ${ }^{53}$,

\footnotetext{
${ }^{51}$ Source: Remuneration of Doctors and Nurses: Progress and Persisting Issues. Joint Sessions of Health Data correspondents and Health Accounts Experts. Paris, 17 October 2013. OECD. https://www.oecd.org/els/health-systems/Item6_Remuneration-of-doctors-and-nurses_Durand.pdf.

52 For example, Cutler et al. (1998) report that the real quality-adjusted price of heartattack treatments declined at an annual rate of 1.1 percent between 1983 and 1994.

53 It should be noted that alcohol consumption between males and females on an annual basis for the period under review was not available. As for tobacco consumption, while separate data series for males and females were available, both have trended down over time and since second-hand smoke can be just as dangerous as first-hand smoke, we opted to use the aggregate data.
} 
DI MATTEO, BARBIERO Health Spending and Outcomes in Canada and Italy

Table 5: Health Status Indicators Determinants Regression Results

\begin{tabular}{|c|c|c|c|c|}
\hline \multicolumn{5}{|l|}{ Dependent Variable: Log of Life Expectancy at Birth in Years } \\
\hline & \multicolumn{2}{|c|}{ Canada } & \multicolumn{2}{|c|}{ Italy } \\
\hline & Coefficient & t-statistic & Coefficient & t-statistic \\
\hline GDP Per Capita in PPP Dollars Lagged One Year & 0.000002 & 9.81 & 0.000003 & (26.80 \\
\hline Alcohol Consumption (Litres per capita) & -0.002733 & -5.35 & -0.000003 & 0.00 \\
\hline Tobacco Consumption (\%15 years plus who smoke) & -0.000538 & -1.64 & -0.003852 & -4.62 \\
\hline $\begin{array}{l}\text { First Difference of Per Capita total Health Expenditure in PPP } \\
\text { Dollars }\end{array}$ & 0.000006 & 0.56 & 0.000000 & 0.03 \\
\hline $\begin{array}{l}\text { First Difference of Social Expenditure Per Capita in PPP } \\
\text { Dollars }\end{array}$ & -0.000002 & -0.48 & -0.000004 & -0.49 \\
\hline Total 1\% Income Share & -0.001271 & -2.43 & 0.000151 & 0.10 \\
\hline Constant & 4.353289 & 325.94 & 4.404139 & 139.96 \\
\hline R-squared & 0.853000 & & 0.875700 & \\
\hline F-Statistic $(6,40)$ & 1238.18 & & 764.73 & \\
\hline \multicolumn{5}{|c|}{ Dependent Variable: Log of Infant Mortality (Deaths per 1000 Live Births) } \\
\hline GDP Per Capita in PPP Dollars Lagged One Year & -0.000016 & -1.83 & -0.000048 & -8.15 \\
\hline Alcohol Consumption (Litres per capita) & 0.137729 & 7.01 & 0.027815 & 2.59 \\
\hline Tobacco Consumption (\%15 years plus who smoke) & 0.013981 & 1.11 & 0.012768 & 0.97 \\
\hline $\begin{array}{l}\text { First Difference of Per Capita total Health Expenditure in PPP } \\
\text { Dollars }\end{array}$ & -0.000633 & -1.60 & -0.000047 & -0.20 \\
\hline $\begin{array}{l}\text { First Difference of Social Expenditure Per Capita in PPP } \\
\text { Dollars }\end{array}$ & 0.000015 & 0.08 & -0.000102 & -0.78 \\
\hline Total 1\% Income Share & 0.051073 & 2.54 & -0.018311 & -0.81 \\
\hline Constant & 0.241695 & 0.47 & 2.454694 & 4.94 \\
\hline R-squared & 0.8109 & & 0.8654 & \\
\hline F-Statistic $(6,40)$ & 100.02 & & 769.09 & \\
\hline
\end{tabular}

Bold denotes significant at 5 percent level; Bold italics is significance at 10 percent level

defined as the percent of population aged 15 years and over who smoke, the first difference of per capita total health expenditure in U.S. PPP\$, the first difference of social expenditures per capita in U.S. PPP\$ ${ }^{54}$ and the income share of the top 1 percent. We use per capita GDP rather than changes in GDP as the determinant of changes in health status given its standard use in the

54 Initial data exploration using LOWESS found that the relationship between life expectancy and the per capita health spending variable or its first difference was increasing. Similarly, the LOWESS plot between infant and per capita health spending or its first difference was a decreasing relationship. As a result, quadratic specifications were not employed. 
literature. ${ }^{55}$ With respect to public spending, changes at the margin are more immediate input factors affecting current health status - therefore, the use of first differences in health and social expenditure. ${ }^{56}$ As in our first set of regressions, Robust regression estimates were done.

Table 5 suggests that for both countries, the level of per capita GDP is a key determinant of increased life expectancy and falling infant mortality for Italy, but not for Canada. Tobacco consumption significantly reduces life expectancy in both countries (but at the 10 percent level for Canada), while alcohol is correlated with reduced life expectancy in Canada but not Italy. Alcohol consumption significantly increases infant mortality in Italy and Canada, while tobacco consumption increases infant mortality in Canada and Italy but is not statistically significant in either country. The health effects of tobacco consumption during pregnancy have been widely known for decades, and the reductions in consumption rates in both countries over time may be a factor in the insignificance of the results with respect to infant mortality.

The effect of marginal changes in total health spending on health outcomes are insignificant drivers of life expectancy and infant mortality in both countries. Moreover, when it comes to social spending, changes in expenditures at the margin are also insignificant contributors to life expectancy and infant mortality. Given the high level of social and economic development of Canada and Italy, it is not surprising that changes in health and social spending at the margin are not significant determinants of health status. Instead, the key drivers appear to be the longterm level of economic development as captured by levels and changes in income, with some influence of tobacco and alcohol use.

As for income distribution and inequality, we find that an increase in the income share of the top $1 \%$ in Canada is statistically significant in decreasing life expectancy and increasing infant mortality. For Italy, an increase in income inequality is not a statistically significant determinant of either life expectancy or infant mortality. While it may be that the effects of income inequality on health outcomes may be weaker in some developed countries with good public health systems, the Canadian results may be driven by the poorer health outcomes among its indigenous peoples. ${ }^{57}$

Another possibility driving Italian results is the large proportion of social transfers devoted to income redistribution, especially for the elderly, which may serve to weaken the effect of market income inequality on life expectancy. We have already noted that in Italy market incomes do not reflect the broader underground economy, which implies that official income figures used also to estimate inequality do not reflect the true extent of either individual or regional inequality in Italy.

\footnotetext{
${ }^{55}$ The health determinants literature focuses on level of income as a key determinant of health spending.

${ }^{56}$ The levels of these two expenditure variables are also highly correlated with GDP.

${ }^{57}$ For discussion, see Ring and Brown (2003) and Smylie and Firestone (2016). It should be noted that it would have been superior to use the Gini coefficients in both countries, but consistent annual data is not available.
} 


\section{MATTEO, BARBIERO Health Spending and Outcomes in Canada and Italy}

Our results tell a consistent story of the determinants of health outcomes. The key determinants in both countries are more closely tied to income, as well as lifestyle choices such as drinking and smoking, rather than interventionist medical care or social spending. If inequality is considered a social determinant, then it matters more for Canada than Italy. The results partly buttress the case for the broader determinants of health status, with socioeconomic factors such as lifestyle choices, per capita income and income distribution as more significant determinants of health outcomes than interventionist health and social spending. ${ }^{58}$

A key result is that medical and social spending alone do not explain health outcomes. Changes in per capita health spending in both Italy and Canada are not significant determinants of either life expectancy or infant mortality. The implication is that over the long-term, per capita income and lifestyle choices (such as tobacco and alcohol consumption) are more important to health outcomes than actual direct expenditures on health services. Yet, social spending is also not a significant determinant of either life expectancy or infant mortality, though income inequality has some effect on health status.

\subsection{Counterfactual Simulation}

As an additional exercise, the regression coefficients in Table 4 for the determinants of the log of total health expenditures are used to perform a counterfactual simulation that asks the following question: Given the actual national performance of Italian GDP, GDP growth, health human resources, technology use and age structure over the period 1970 to 2016, what would per capita total health spending look like if the same data was combined with the regression coefficients from Canada's total health expenditure regression to construct an alternative fitted value that could then be compared to the original Italian ones? Similarly, such an alternative health expenditure estimate is also computed for Canada using its own data values but the Italian regression coefficients.

The results are presented in Appendix 1. For both countries, as expected, their actual and fitted results move quite closely together, suggesting the estimated models do a good job of explaining their real per capita total health spending. What is also interesting is the result when their own numbers are plugged into the other country's regression.

For Canada, the Italian coefficients generate rising counterfactual health spending over time that tracks its actual spending, but usually at a lower level and with some interesting larger divergences - the early 1980 s and much of the 1990 s plus a period in the early 2000 s. These periods of decline in counterfactual health spending occurred during times of recession or slow economic growth. The Italian coefficients make Canadian health spending more sensitive to changes in GDP.

\footnotetext{
${ }^{58}$ For an overview of the social determinants of health, see Braveman, Egerter and Williams (2010).
} 
Substituting Italy's numbers into Canada's regression generates a large surge in per capita Italian spending relative to actual expenditures over the period 1970 to approximately the mid -1990s. This result suggests that up until the 1990s, the Canadian health system was more costly compared to the Italian health system. Given the same economic and demographic inputs, Canada spent more. However, the 1990s were a tumultuous time in Canadian public spending and health spending since the federal fiscal crisis generated major changes in Canadian intergovernmental transfers that ultimately placed health care spending on a lower growth trajectory compared to the period prior to 1990. In the Italian case, when combined with its weaker overall economic growth performance over the period since the late 1990s - it generates a sustained decline in per capita health spending. Indeed, annual real GDP growth in Italy from 1995 to 2017 averaged barely 1 percent while in Canada it was just over 2 percent.

\section{Discussion}

It is not possible to definitively conclude from our results that one system is "more efficient" than the other given the differences in the economies, societies and health system structures of Canada and Italy. We need to acknowledge the challenges associated with measuring and comparing the value for money or cost-effectiveness of these two-health care system. For example, we chose to emphasize infant mortality and the length of life as an indicator of the "output" of the healthcare system, but more difficult to measure and ascertain is the quality of extra years of life.

With respect to income as a health spending driver, it is a significant long-term driver of per capita Canadian health spending, but short-term fluctuations in GDP are not, as opposed to Italy which seems to exhibit an opposite response to these variables. Our results suggest the Canadian health system has more long-term structural inertia with respect to resource use, while Italian health spending is more responsive to short term income fluctuations. The difference in response may be the result of institutional differences given that Canadian health care provision is quite decentralized compared the Italian health care system.

Physician numbers have similar positive effects on health spending in Canada and Italy, but the number of nurses is more important for Italy. These results point to the similar role of physicians as gatekeepers to the system in both countries. But in the Italian case, given that there are more physicians, the public health system may have had more incentive to restrain physician expenditure through the remuneration system. With respect to the impact of nursing numbers, the difference may be due to differences in aspects of health care provision such as the reliance on family to provide some of the hospital-based care in Italy - most likely an important factor given the relatively low number of nurses in Italy compared to Canada. Adding nurses substitutes positive amounts of spending for what essentially is being provided 
for free by family members. Moreover, given the relatively lower number of nurses in Italy, if more nurses were added, it would operate to increase health expenditures at the margin. We have already noted that the lower salaries of both medical doctors and nurses is a contributing cost factor in the lower spending of the Italian health care system.

For Canada, increasing units of diagnostic technology per capita is associated with a decrease in per capita health spending at both the total and public level. For Italy, the result is positive, though only significant at the $10 \%$ level for public health care spending. It could be that the early diffusion of diagnostic technology helped reduce health care costs via more accurate and earlier diagnosis, and Canada has lagged Italy in the diffusion of this technology. However, over time increases in the technology may contribute more to costs than to benefits as more anomalous findings - or incidentalomas are generated - which merit further and costlier follow up. ${ }^{59}$ The role of diagnostic imaging in affecting health costs is an area of some debate in the health economics literature and the results here do not resolve this debate. ${ }^{60}$

While Italy has a higher proportion of population aged 65 years and over, aging is a more significant driver of health spending in Canada. By 2017, the proportion of population aged 65 years and over was 17 percent in Canada and 23 percent in Italy. The results for Italy could be due to the percentage of the population over 65 began growing at an earlier point in time, sparking more advanced health sector cost control measures. Or, it could reflect an institutional difference whereby more of the health needs of the elderly are met outside the health care system in Italy compared to Canada. For example, the result of families and private personal care workers providing care.

In Italy health costs have been restrained in the elderly population through the wide-spread hiring of foreign in-home elder care workers (the badante) ${ }^{61}$. The Italian government provides families with cash supplements to hire in-home elder care workers. Thus, what appears at first to be cost reducing measures in providing for the elderly, is in fact a bit of a mirage; resources spent for elderly care come from the social expenditure category.

Ultimately, Canada spends a larger share of its GDP and greater amounts per capita on health than Italy while Italy has somewhat better outcomes. Given Canada's higher per capita GDP relative to Italy, all this may simply mean is that Canada is willing and able to spend more on health. However, this is not a satisfactory explanation given that while it may explain differences between the Canadian and U.S. health systems - which are quite different - it

\footnotetext{
${ }^{59}$ Wagner and Aron (2012).

${ }^{60}$ For some literature in this area, see Beinfeld and Gazelle (2005), Sullivan (2014) and Marchildon and Di Matteo (2011).

${ }^{61}$ See Gori, 2012
} 
remains that both Canada and Italy have largely public single payer systems with many similarities. ${ }^{62}$

One possibility is that there may indeed be differences in health outcomes due to lifestyle choices making it possible for the Italian system to spend less relative to Canada and yet achieve better outcomes. Indeed, the regression results for Italy and Canada show that over the longterm, lifestyle choices may be more important to health outcomes than actual direct expenditures on health services. Another possibility is that there may be something about the role and structure of health care that differs across the two countries. To examine this hypothesis, we employed a counterfactual to determine whether health spending in Italy and Canada would be different if the relationship driving health spending was that of the other country. The results suggest that something about the structure of the determinants of Canadian health spending resulted in more spending, all other things given.

Higher present Canadian health spending levels relative to Italy are a function of historical inertia combined with stronger economic growth. Going back to the 1970s, the level of health spending in Canada was higher compared to Italy. At the same time, since the 1970s, Italy has shown greater improvements in mortality and life expectancy than Canada. Italy does spend less per capita for equivalent or better outcomes but this may not necessarily mean that Italy has been able to get greater value for money per additional health dollar spent because it is based on levels of spending rather than the responsiveness of outcomes to changes in spending which is what a measure of cost effectiveness should do.

Canadian total per capita health spending from 1970 to 2017 in US\$ PPP grew from \$289 to $\$ 4826$ - an increase of 1,570 percent. Meanwhile, infant mortality declined 77 percent and life expectancy at birth rose 14 percent. Over the same period, Italian health spending in US\$ PPP rose from $\$ 172$ to $\$ 3,541$ - an increase of 1,959 percent. However, infant mortality fell 90 percent and life expectancy at birth grew 17 percent. From these numbers, the elasticity of infant mortality decline with respect health spending is -0.049 for Canada and -0.046 for Italy. The elasticity of life expectancy at birth to per capita health spending is 0.009 for Canada and 0.009 for Italy. When examined in additional dollars spent at the margin, outcomes in Canada and Italy are the same. However, Canada achieves these results with a higher level of spending per capita, which is shaped by higher costs, particularly with respect to health professional compensation.

\footnotetext{
${ }^{62}$ In the case of Canada and the United States, the U.S. far outspends Canada on health care with poorer outcomes with respect to health indicators. Much of the difference in spending was due to Canadians spending less on physicians and hospitals relative to the United States, higher administrative costs in the United States and higher incomes in the U.S. and more intensive provision of medical procedures. Pozen and Cutler (2010).
} 
DI MATTEO, BARBIERO Health Spending and Outcomes in Canada and Italy

\section{Conclusion}

The greater levels of per capita health spending in Canada relative to Italy are largely a function of initial conditions rooted in Canada's higher economic output and historically higher salaries for medical professionals. Our results also suggest that the most important determinants of health outcomes in both Canada and Italy appear to be per capita income and to a lesser extent, lifestyle variables, such as alcohol and tobacco consumption.

Our results give credence to Anderson et. al. (2000), Golinelli et.al (2018), and Cremieux et.al (1999) that health expenditures have some positive impact on health outcomes, but that complex lifestyle forces also matter. It may also be that once health spending has reached a certain level in high income countries, diminishing returns set in and additional spending increments contribute little health indicators such as life expectancy or infant mortality.

As for the role of social spending being more important than health spending, our results suggest social spending is not a significant driver of health outcomes in Canada or Italy - which spends a larger share of its GDP on social expenditures relative to Canada with much of the difference accounted for by the more generous public pension system in Italy. Rubin et. al. (2016) show that old-age spending appears to make a significant contribution to better health outcomes but suggest that social spending and protection may be more important to better health outcomes in societies in which income inequality is high. Lynch et. al. (2004) also argue that reducing inequality of the most disadvantaged population can improve health outcomes. Neither Italy nor Canada have very high-income inequality, which may explain why social spending is not the main determinant of health outcomes in either country. Moreover, generous Italian pensions for the elderly started soon after 1945, which may explain why higher social spending in Italy did not impact our results.

Our results reinforce Latif (2015): income inequality is not nearly as important to health outcomes compared to the level of absolute income. Canada does spend more on health care relative to Italy, but based on the responsiveness of basic indicators to increase in health spending over time, each additional dollar spent on health in Canada and Italy appears to have yielded the same increments in life expectancy increases and infant mortality declines in the period since 1970. Canada and Italy therefore are equivalent in terms of the cost effectiveness of additional dollars spent on health as measured by our outcomes.

Canada spends more on health care for historical and institutional reasons with higher remuneration for physicians and nurses a contributing factor. For nurses, Canada has more of them per capita while Italy has fewer and their salaries are less than nurse incomes in Canada. Canadian doctors are paid much more than Italian doctors. The higher income for Canadian doctors is at least partly attributable to the fee-for-service model, compared to the capitation 
model in Italy. This suggests that Canada's seeming tendency to spend more and get less is a result of historical long-term spending patterns and factors which have had a long-term structural impact on the efficiency of the Canadian health care system.

\section{References}

Afonso A and St. Aubyn M. (2006) Relative Efficiency of Health Provision: A DEA Approach With Non-Discretionary Inputs. 2006. http://www.iseg.utl.pt/departamentos /economia/wp/wp332006deuece.pdf.

Anderson, G.F., Hurst, J. Hussey, P.S. and Jee-Hughes, M. (2000) Health Affairs, May/June 2000, Vol. 19, Number 3.

Anderson, G.F. and Frogner, B.K. (2008). Health Spending in EOCD Countries: Obtaining Value per Dollar. Health Affairs, Nov-Dec. (6):17:18-27

Ariste, R. and L. Di Matteo (2017) "Value for money: an evaluation of health spending in Canada," International journal of Health Economics and Management, 17: 289-310.

Ariste, R., and J. Carr. 2003. New considerations on the Empirical Analysis of Health Expenditures in Canada: 1966-1998. Ottawa, Ontario: Health Canada, Health Policy Research Working Paper Series, Working Paper 02-06.

Asandului, L., M. Roman, P. Fatulescu (2014) "The efficiency of healthcare systems in Europe: a Data Envelopment Analysis approach," Procedia Economics and Finance, 10, 261-268.

Babazono, A., \& Hillman, A. (1994). A Comparison of International Health Outcomes and Health Care Spending. International Journal of Technology Assessment in Health Care, 10(3), 376-381. doi:10.1017/S0266462300006619

Barros, P.P. 1998. "The Black Box of Health Care Expenditure Determinants." Health Economics 7: 553-544.

Barua, B., S. Hasan and I. Timmermans (2017). Comparing Performance of Universal Health Care Countries, 2017. Fraser Institute.

Beinfeld, M.T. and G.S. Gazelle (2005) "Diagnostic Imaging Costs: Are They Driving up the Costs of Hospital Care?” Radiology, 235, 3, https://doi.org/10.1148/radiol.2353040473

Bradley E.H. and Taylor, L.A. (2013) The American Health Care Paradox: Why Spending More is Getting Us Less, Public Affairs, New York, N.Y.

Bradley, E.H, Elkins, B.R., Herrin, J., and Elbel, P. (2011). Health and Social Services Expenditures: Associations With Health Outcomes. BMJ Qual Saf Oct;20(10):826-31.

Braendle, T. and C. Columbier (2016) "What drives public health care expenditure growth? Evidence from Swiss cantons, 1970-2012," Health Policy, 120, 9, September, 1051-1060.

Braveman, P., S. Egertr and D.R. Williams (2011) "The Social Determinants of Health: Coming of Age,"Annual Review of Public Health, 32, 381-98. 
DI MATTEO, BARBIERO Health Spending and Outcomes in Canada and Italy

Canadian Institute for Health Information (2018). National Health Expenditure Trends 2018, 1975 to 2017.

Canadian Institute for Health Information (2016). Canada's International Health System Performance Over 50 Years: Examining Potential Years of Life Lost. Ottawa, ON: CIHI

Canadian Institute for Health Information (2014), "Health System Efficiency in Canada: Why Does Efficiency Vary Among Regions?” Ottawa, ON: CIHI

Canadian Institute for Health Information. (2012). Developing a Model for Measuring the Efficiency of the Health System in Canada. Ottawa, ON: CIHI

Cantarero Prieto, D. and Lago Peñas, S. (2010): “The determinants of health careexpenditure in Spain: a re-examination", Applied Economics Letters, 17(7-9), 723-726.

Cavalieri, M. Guccio, C. (2006), Health Expenditure in Italy: A Regional Analysis of the Public-Private Mix, Dipartimento di Economia Pubblica e Territoriale, University di Pavia https://pdfs.semanticscholar.org/f514/f83059b503625cb28776f6392da19ed38a71.pdf

Cicchetti, A, Gasbarrini, A (2016), "The healthcare service in Italy: regional variability," European Review for Medical and Pharmacological Science, Vol 20 (1 suppl), 1-3

Clarke, J. (2016) Difficulty accessing health care services in Canada. Health at a Glance. Statistics Canada. Catalogue no.82-624-X. https:/www150.statcan.gc.ca/n1/en/pub/82624-x/2016001/article/14683-eng.pdf?st=oWNTo5Jc

Constant, A., S. Peterson, C.D. Mallory and J. Major. 2011. Research Synthesis on cost Drivers in the Health Sector and Proposed Policy Options. Ottawa, ON: Canadian Health Services Research Foundation, Reports on Cost Drivers and Health System Efficiency: Paper 1.

Cremieux, P. Y., Meilleur, M. C., Ouellette, P., Petit, P., Zelder, M., \& Potvin, K. (2005a). Public and private pharmaceutical spending as determinants of health outcomes in Canada, Health Economics, 14(2), 107-116.

Cremieux, P. Y., Ouellette, P., \& Pilon, C. (1999). Health care spending as determinants of health outcomes. Health Economics, 8, 627-639.

Crivellei, L., M. Filippini and I. Mosca (2006): "Federalism and regional healthcare expenditures: an empirical analysis for the Swiss cantons," Health Economics, 15(5), 535541.

Cutler, D.M., et al. 1998. "Are Medical Prices Declining? Evidence from Heart Attack Treatments.” Quarterly Journal of Economics, 113(4): 991-1024.

Di Matteo, L. (2014) "Physician numbers as a driver of provincial government health spending in Canadian health policy," Health Policy, 115, 1, 18-35.

Di Matteo, L. (2010). "The sustainability of public health expenditures: evidence from the Canadian federation.” European Journal of Health Economics, 11 (6): 569-584. 
Di Matteo, L. and R. Di Matteo. (1998). "Evidence on the Determinants of Canadian Provincial Government Health Expenditures: 1965-1991." Journal of Health Economics 17(2): 211228.

Di Matteo, L. and J.C.H. Emery (2014) "Common provincial determinants and cost drivers," Chapter 4, co-authored with J.C.H. Emery, in Bending the Cost Curve in Health Care: Canada's Provinces in International Perspective, eds. G.P. Marchildon and L. Di Matteo. The Johnson-Shoyama Series on Public Policy, University of Toronto Press.

Dutton, D.J., P-G Forest, R.D. Kneebone, J.D. Zwicker (2018) "Effect of provincial spending on social services and health care on health outcomes in Canada: an observational longitudinal study" CMAJ, January 22 $2^{\text {nd }}$, Vol. 190, No. 3, E66-E71.

Ferré F, de Belvis AG, Valerio L, Longhi S, Lazzari A, Fattore G, Ricciardi W MA.(2014). Italy: Health System Review. Health Systems in Transition, 2014. 2014. Available from: http://www.euro.who.int/ data/assets/pdf file/0003/263253/HiT-Italy.pdf?ua=1

Filmer, D.,\&Pritchett, L. (1999). The impact of public spending on health: Does money matter? Social Science and Medicine, 49, 1309-1323.

Folland, S., A.C. Goodman and M. Stano (2017) The Economics of Health and Health Care, $8^{\text {th }}$ edition, Routledge: New York.

Francese, M. and Romanelli, M. (2011). "Healthcare in Italy: Expenditure Determinants and Regional Differentials," Banca D'Italia Working Papers, No. 828

Gerdtham, U.G., J. Sogaard, F. Andersson and B. Jonsson. (1992). "An econometric analysis of health care expenditure: A cross-section study of the OECD countries," Journal of Health Economics 11: 63-84.

Gerdtham, U.G., B. Jonsson, M. MacFarlan and H. Oxley. (1998). "The Determinants of Health Expenditure in the OECD Countries: A Pooled Data Analysis," P. Zweifel, ed. Health, The Medical Profession and Regulation. Developments in Health Economics and Public Policy 6: 113-134.

Gerdtham, U.G. and B. Jonsson. (2000). "International Comparisons of Health Expenditure: Theory, Data and Econometric Analysis," Handbook of Health Economics, Vol. 1, eds. A.J. Culyer \& J.P. Newhouse. Elsevier Science.

Golinelli, D., Bucci, A., Toscano, F., Filicolori, F., and Fantini, P (2018), BMC Health Services Research 18:671

Gori, C. (2012). Home care in Italy: a system on the move, in the opposite direction of what we expect. Special Issue: Reforming Home Care in Ageing Societies, Vol. 20, Issue 3. https://doi.org/10.1111/j.1365-2524.2011.01052.x

Guindon, G. E., \& Contoyannis, P. (2012). A second look at pharmaceutical spending as determinants of health outcomes in Canada. Health Economics, 21, 1477-1495. 
DI MATTEO, BARBIERO Health Spending and Outcomes in Canada and Italy

Hitiris, T. and J. Posnett. (1992). "The determinants and effects of health expenditure in developed countries." Journal of Health Economics 11: 173-181.

Hollingsworth B.(2008) The measurement of efficiency and productivity of health care delivery. Health Economics, 17(10):1107-1128.

Hurley, J. (2010) Health Economics, First Edition. McGraw-Hill Ryerson.

Jacobs R, Smith PC, Street A (2006). Measuring Efficiency in Health Care: Analytic Techniques and Health Policy. Cambridge, U.K.: Cambridge University Press

Joumard, I., C. André and C. Nicq (2010), "Health CareSystems: Efficiency and Institutions", OECD Economics Department Working Papers, No. 769, OECD Publishing, Paris.

Kim, D., \& Saada, A. (2013). The social determinants of infant mortality and birth outcomes in Western developed nations: a cross-country systematic review. International Journal of Environmental Research and Public Health, 10(6), 2296-2335.

Lavis JN. (2011). Dialogue Summary: Measuring Health System Efficiency in Canada. Hamilton, ON: McMaster Health Forum.

Latif, E. (2015). Income Inequality and Health: Panel Data Evidence from Canada. The BE Journal of Economic Analysis \& Policy, 15(2), 927-959.

Leu, Robert E. (1986). "The public-private mix and international health care costs," in Public and Private Health Services, edited by A.J. Culyer and B. Jonsson, 41-63. Oxford: Basil Blackwell.

Lozano, R. et al., (2018) Measuring performance on the Healthcare Access and Quality Index for 195 countries and territories and selected subnational locations: a systematic analysis from the Global Burden of Disease Study 2016, The Lancet, 391, 2236-71.

Lynch J, Davey Smith G, Hillemeier M, Shaw M, Raghunthan T, Kaplan G. (2001) "Income Inequality, the Psychosocial Environment, and Health: Comparisons of Wealthy Nations". Lancet. 358:194-200.

Lynch, J., Smith, G.D., Harper, S. Hillemeier, M. Ross, N., Kaplan, G.A., and Wolfson, M. (2004). Is Income Inequality a Determinant of Population Health?: A Systematic Review, The Milbank Quarterly, Vol 82, No. 1 pp.5-99

Magazinno, C. and M. Mele (2012) "The Determinants of Health Expenditures in Italian Regions" International Journal of Economics and finance, 42, March, 61-72.

Marchildon, G. (2019) "Health system in Canada," Health Services Evaluation, 769-777 https://doi.org/10.1007/978-1-4939-8715-3_41

Marchildon, G. and L. Di Matteo (2011) Health Care Cost Drivers: The Facts. Canadian Institute for Health Information. 
D. Martin, A.P Miller, A. Quesnel-Vallée, N.R Caron, B. Vissandjée, G..P Marchildon (2019). "Canada's universal health-care system: achieving its Potential," 11-28, The Lancet. www.thelancet.com. Published online February 23, 2018 http://dx.doi.org/10.1016/S01406736(18)30181-8.

Medeiros, J. and Schwierz, C. (2015). The Efficiency Estimates of Health Care Systems. European Commission, Economic Paper 549.

Medina, L., and Schneider, F. (2018). Shadow Economies Around the World: What Did We Learn Over the Last 20 Years? IMF Working Paper WP/18/17

Nolte, E., \& McKee, M. (2004). Does healthcare save lives? Avoidable mortality revisited. London: The Nuffield Trust.

Nghiem, S. H. and L.B. Connelly (2017) "Convergence and determinants of health expenditures in OECD countries". Health Econ Rev 7, 29 (2017). https://doi.org/10.1186/s13561-017-0164-4

Nixon, J., \& Ulmann, P. (2006). "The relationship between health care expenditure and health outcomes: Evidence and caveats for a causal link". European Journal of Health Economics, $7,7-18$.

Norris, S. (2018). Federal funding for Health Care. Library of Parliament. Publication No. 2018-45-E $18 \quad$ July 2018. https://lop.parl.ca/staticfiles/PublicWebsite/Home/ResearchPublications/InBriefs/PDF/201 8-45-e.pdf

OECD 2010, "Health care systems: Getting more value for money", OECD Economics Department Policy Notes, No. 2.

Parkin, D., A. McGuire and B. Yule. (1987). "Aggregate Health Care Expenditures and National Income: Is Health Care a Luxury Good.” Journal of Health Economics 6: 109-27.

Pozen, A. and D.M. Cutler (2010) "Medical Spending Differences in the United States and Canada: The Role of Prices, Procedures and Administrative Expenses," Inquiry, 47(2), 124134.

Ring, I., Brown, N. (2003). The health status of indigenous peoples and others. BMJ (Clinical research ed.), 327(7412), 404-405. https://doi.org/10.1136/bmj.327.7412.404

Rowlingson, K. (2011) Does income inequality cause health and social problems?" Joseph Rowntree Foundation. www.jrf.org.uk

Rubin, J. Taylor, J., Krapels, J., Sutherland, A., Felician, M., Liu, J. Davis, L., and Rohr, C. (2016), Are Better Health Outcomes Related to Social Expenditure? Rand Corporation, Cambridge, U.K. 
Smylie, J. and M. Firestone (2016) The health of Indigenous Peoples. In Dennis Raphael (Ed.), Social determinants of health: Canadian perspectives, 3rd edition. (434-466). Toronto, ON: Canadian Scholars' Press.

Snowden, C. (2011). The Spirit Level of Delusion: Fact-Checking the Left's New Theory of Everything. Monday Books

Stuckler D, Basu S, McKee M. Budget crises, health, and social welfare programs. BMJ. 2010;340:c3311. Available from: http://www.ncbi.nlm.nih.gov/pubmed/20576709

Subramanian, S.V. and I. Kawachi (2004) "Income Inequality and Health: What we Have Learned So Far," Epidemiologic Reviews, 26, 1, July, 78-91.

Sullivan, B. (2014) "Innovation in medical imaging can help keep health care affordable," The Hill Times. November 17, 43.

Thorne, S. (1996) "In Italy, A Medical Degree Often Means Unemployment or Underemployment." Canadian Medical Association Journal, 154 (6), March 15, 1996.

Vercelli M, Lillini R, Quaglia A, Micale RT, La Maestra S, De Flora S. (2014) Age-related mortality trends in Italy from 1901 to 2008. PLoS One. 2014;9(12):e114027. Available from: http://www.ncbi.nlm.nih.gov/pubmed/25486606

Wagner, J. \& DC Aton (2012) "Incidentalomas: a "disease" of modern imaging technology." Best Pract Res Clin Endocrinol Metab. 2012 Feb;26(1):3-8. doi: 10.1016 jj.beem.2011.08.006.

Walton, J. and Binns, T.B.(ed) (1984). Medical Education and Manpower in the EEC. Fondazione Smith Kline.

Wilkinson, R. and Picket, K. (2009). The Spirit Level: Why more equal societies almost always do better. Allan Lane

Wilkinson, R. and Picket, K. (2009). (2015). Income Inequality and Health: A causal review. Social Science and Medicine, Vol. 128, Pages 316-326

World Health Organization (2010) Health Systems Financing: The path to universal coverage.

Elizabeth H. Bradley, Maureen Canavan, Erika Rogan, Kristina Talbert-Slagle, Chima Ndumele, Lauren Taylor and Leslie A. Curry "Variation In Health Outcomes: The Role Of Spending On Social Services, Public Health, And Health Care, 2000-09," Health Affairs 35 , no.5 (2016):760-768

World Health Organization (2000). The World Health Report 2000: Health Systems: Improving Performance. Geneva: WHO

Yetim,B., G. İlgün, Y. Çilhoroz, Ş. Demirci \& M. Konca (2020) The socioeconomic determinants of health expenditure in OECD: An examination on panel data, International Journal of Healthcare Management, DOI: 10.1080/20479700.2020.1756112 


\section{Appendix 1: Counterfactual Simulation}

Figure A1.1: Canada: Counterfactual Simulations (Log of Per Capita Total health Expenditure)

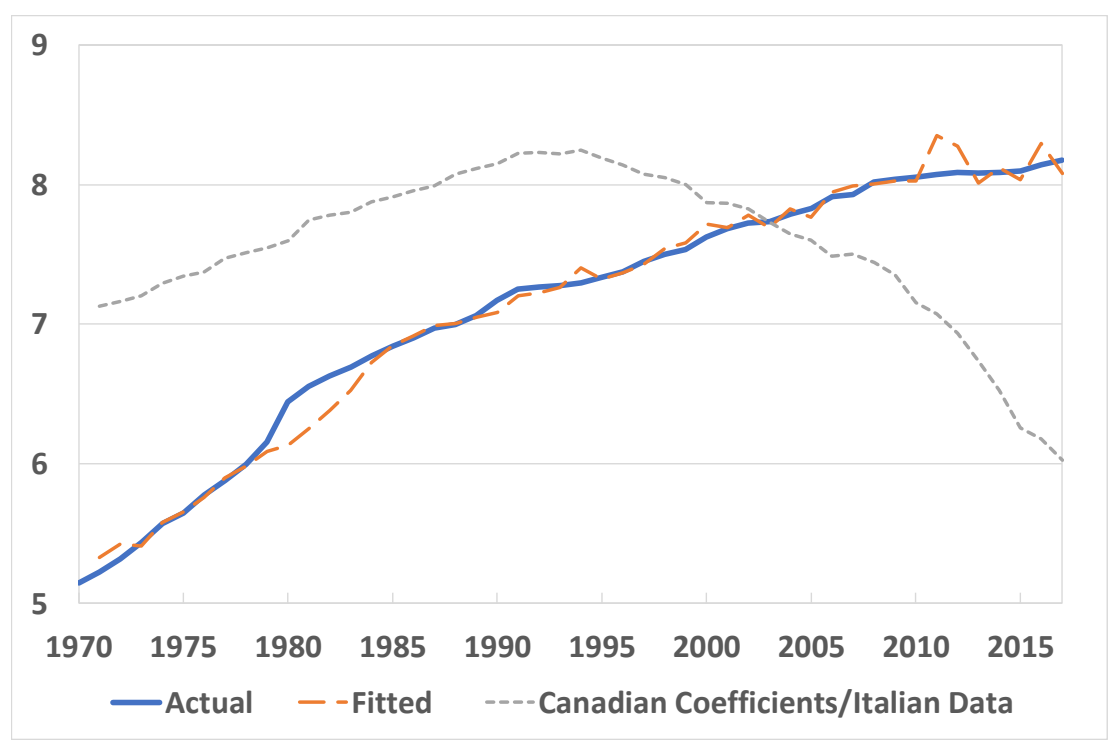

Figure A1.2: Italy: Counterfactual Simulation (Log of Per Capita Total Health Expenditures)

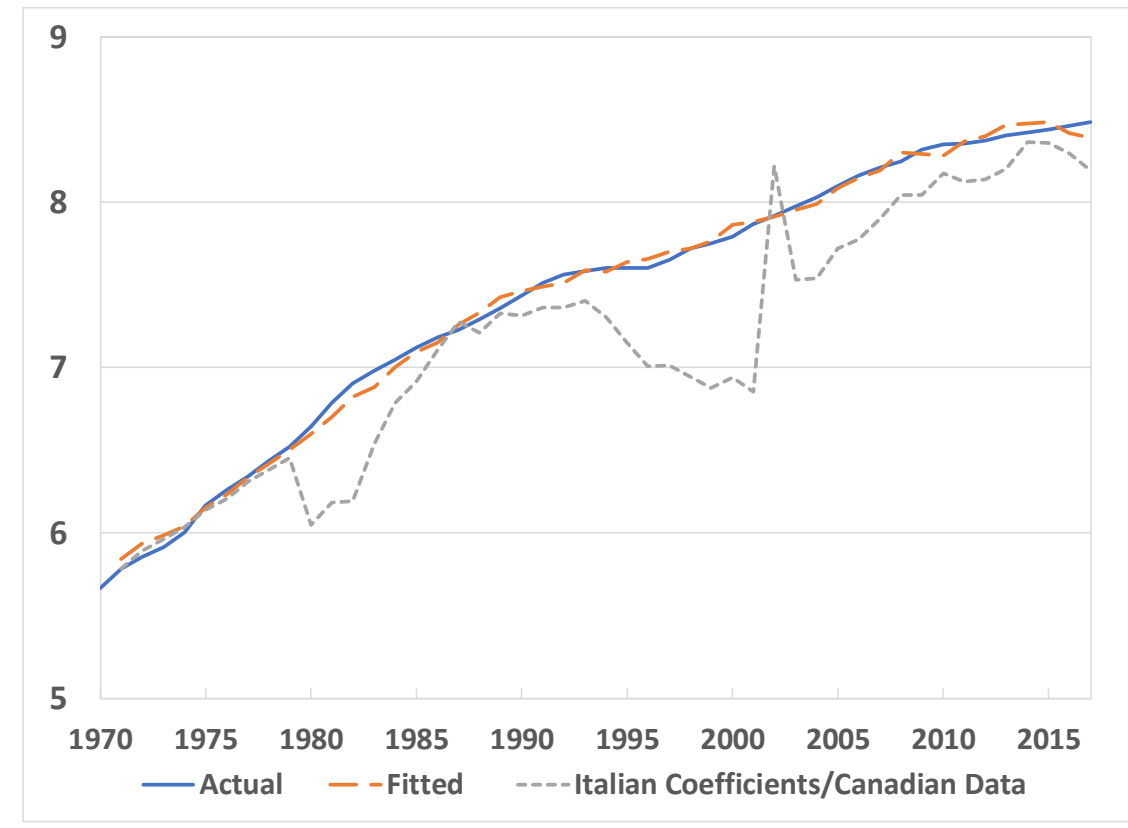

